\title{
CMA GC: Doctors must engage in climate change action
}

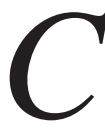

$M A J$ is reporting from the 149th Annual Meeting and General Council of the Canadian Medical Association (CMA), being held in Vancouver Aug. 21-24. Issues to be discussed this year include drug shortages, a new health accord, social media and climate change.

\section{Doctors must engage in climate change action}

The spread of Lyme disease. Record high temperatures for two years running. Massive wildfires. All have affected the health of Canadians and all are related to climate change, argued international humanitarian Dr. James Orbinski in his keynote address at the CMA annual meeting today. Doctors have a professional responsibility to get involved, said the University of Toronto professor who cofounded Médecins Sans Frontières Canada (1991) and Dignitas International."CMA showed enormous engagement until around 2010." In 2009, CMA contributed to the World Medical Association policy on climate change and then developed its own action plan. "The time now is ripe for an even stronger assertion and an even stronger engagement."

Read full article

\section{Assisted-death debate not yet put to rest}

Legalizing assisted death is only the beginning of the end-of-life conversation, delegates to the CMA General Council heard in an ethics session on Aug. 22.

Canada introduced federal legislation allowing assisted death for some

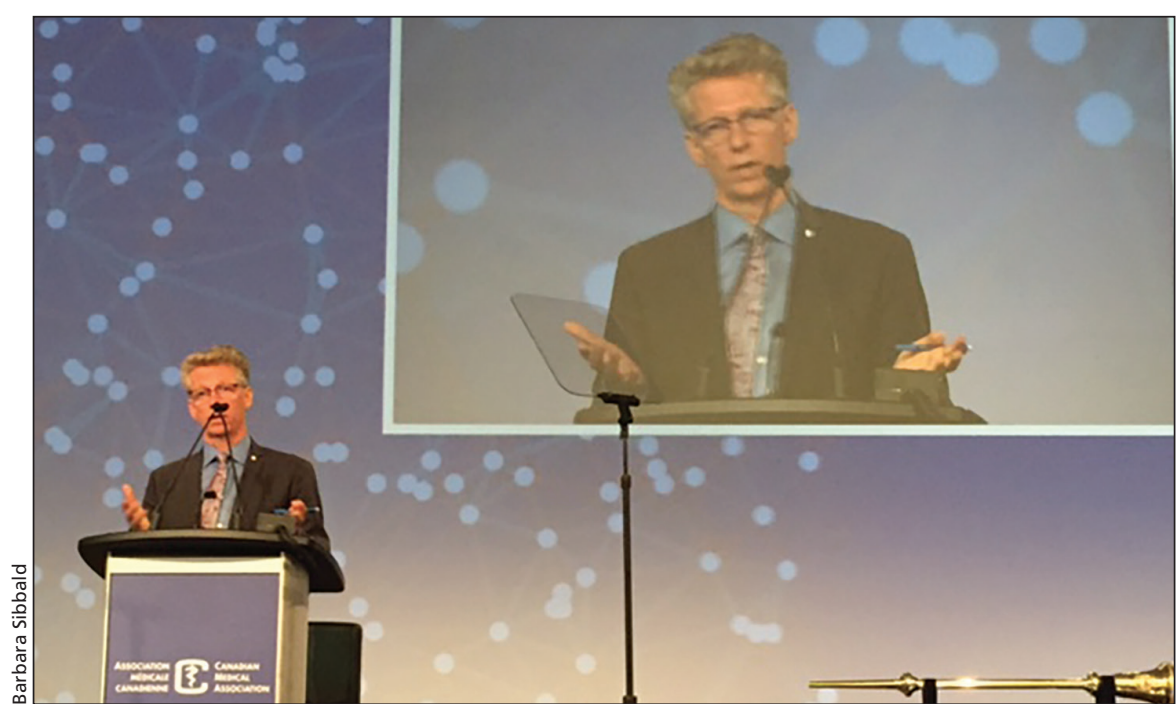

Dr. James Orbinski urged the CMA to establish a standing committee on health and climate change during his keynote address. adults on June 17. Now it's up to provincial-territorial governments, professional regulators and medical institutions to determine where and how the service is provided. "The profession is divided on the issue of assisted dying, and this is as true today as when we started the conversation," said Dr. Jeff Blackmer, CMA's vicepresident of medical professionalism. Read full article

\section{The meaning of autonomy in medicine}

At first, the discussion focused on the importance of physician autonomy. Then it shifted to a question: What exactly do we mean by "autonomy" in medicine? Finally, near the end of the discussion, one physician made a suggestion: let's use another word.

"Could we consider replacing the word 'autonomy' - it flies in the face of what we have been talking about: collaboration, integration, teamwork, et cetera - and consider the word 'responsibility'?" Dr. Jasneet Parmar of Alberta asked today at a session on emerging issues in health at the annual meeting of the CMA.

Read full article

\section{Assisted death in Canada: what you need to know}

A recap of the debate surrounding the legalization of medical aid in dying.

Read full article

— Roger Collier, CMAJ

CMAJ 2016. DOI:10.1503/cmaj.109-5318 